\title{
Comprehensive phenotyping of neuropsychiatric traits in a multiplex $3 q 29$ deletion family: a case report
}

Melissa M. Murphy' ${ }^{1}$ T. Lindsey Burrell ${ }^{2,3}$, Joseph F. Cubells ${ }^{4}$, Michael T. Epstein ${ }^{5}$, Roberto Espana ${ }^{6}$, Michael J. Gambello ${ }^{1}$, Katrina Goines ${ }^{6}$, Cheryl Klaiman ${ }^{2,3}$, Sookyong Koh ${ }^{2}$, Rossana Sanchez Russo ${ }^{1}$, Celine A. Saulnier ${ }^{2,7}$, Elaine Walker ${ }^{6}$, The Emory $3 q 29$ Project and Jennifer Gladys Mulle ${ }^{1,8^{*}}$

\begin{abstract}
Background: 3q29 deletion syndrome is associated with a range of medical, neurodevelopmental, and psychiatric phenotypes. The deletion is usually de novo but cases have been reported where the deletion is inherited from apparently unaffected parents. The presence of these unaffected or mildly affected individuals suggests there may be an ascertainment bias for severely affected cases of 3q29 deletion syndrome, thus the more deleterious consequence of the 3q29 deletion may be overestimated. However, a substantial fraction of 3q29 deletion syndrome morbidity is due to psychiatric illness. In many case reports, probands and transmitting parents are not systematically evaluated for psychiatric traits. Here we report results from a systematic phenotyping protocol for neurodevelopmental and neuropsychiatric traits applied to all 3q29 deletion carriers in a multiplex family.

Case presentation: Through the 3q29 registry at Emory University, a multiplex family was identified where three offspring had a paternally inherited 3q29 deletion. We evaluated all 4 3q29 deletion family members using our previously described standardized, systematic phenotyping protocol. The transmitting parent reported no psychiatric history, however upon evaluation he was discovered to meet criteria for multiple psychiatric diagnoses including previously undiagnosed schizoaffective disorder. All four 3q29 deletion individuals in the pedigree had multiple psychiatric diagnoses that interfered with quality of life and prohibited successful academic and occupational functioning. Cognitive ability for all individuals was average or below average, but within the normal range.

(Continued on next page)
\end{abstract}

\footnotetext{
* Correspondence: jmulle@emory.edu

'Department of Human Genetics, Emory University School of Medicine,

Whitehead 305M, 615 Michael Street, Atlanta, GA 30322, USA

${ }^{8}$ Department of Epidemiology, Rollins School of Public Health, Emory

University, Atlanta, USA

Full list of author information is available at the end of the article
}

(c) The Author(s). 2020 Open Access This article is licensed under a Creative Commons Attribution 4.0 International License, which permits use, sharing, adaptation, distribution and reproduction in any medium or format, as long as you give appropriate credit to the original author(s) and the source, provide a link to the Creative Commons licence, and indicate if changes were made. The images or other third party material in this article are included in the article's Creative Commons licence, unless indicated otherwise in a credit line to the material. If material is not included in the article's Creative Commons licence and your intended use is not permitted by statutory regulation or exceeds the permitted use, you will need to obtain permission directly from the copyright holder. To view a copy of this licence, visit http://creativecommons.org/licenses/by/4.0/ The Creative Commons Public Domain Dedication waiver (http://creativecommons.org/publicdomain/zero/1.0/) applies to the data made available in this article, unless otherwise stated in a credit line to the data. 


\begin{abstract}
(Continued from previous page)
Conclusions: This is the first case report of inherited 3q29 deletion syndrome where all affected individuals in the pedigree have been comprehensively and systematically evaluated for neurodevelopmental and psychiatric symptoms, using a standard battery of normed instruments administered by expert clinicians. Our investigation reveals that individuals with $3 q 29$ deletion syndrome may have psychiatric morbidity that is debilitating, but only apparent through specialized evaluation by an expert. In the absence of appropriate evaluation, individuals with 3q29 deletion syndrome may suffer from psychiatric illness but lack avenues for access to care. The individuals evaluated here all have cognition in the normal range alongside multiple psychiatric diagnoses each, suggesting that cognitive ability alone is not a representative proxy for $3 q 29$ deletion-associated disability. These results require replication in a larger cohort of individuals with 3q29 deletion syndrome.
\end{abstract}

Keywords: 3q29 deletion, Schizophrenia, Psychosis, ADHD, CNV disorder, Evaluation of genetic syndromes, Case Report

\section{Background}

Individuals with 3q29 deletion syndrome are hemizygous for a $1.6 \mathrm{Mb}$ interval containing 21 protein coding genes [1]. The syndrome is associated with a range of physical abnormalities, including heart defects, ocular abnormalities, and recurrent ear infections [2,3]. Recent reports find that individuals with $3 \mathrm{q} 29$ deletion syndrome have increased susceptibility for neurodevelopmental and neuropsychiatric phenotypes, including mild to moderate intellectual disability, autism spectrum disorder (ASD), generalized anxiety disorder, and a remarkable 40-fold increased risk for schizophrenia [3-8]. The syndrome has most often been described in case reports, and these data have shaped our current understanding of the syndrome [1, 2, 9-27]. However, case reports often describe only physical exam results and do not include comprehensive neuropsychiatric evaluation with gold-standard instruments. Systematic descriptions of the neurodevelopmental and psychiatric phenotypes are emerging, but these have relied upon self-report of phenotypes [3, 7]. A comprehensive, unbiased characterization of the syndrome is needed.

While the syndrome is most frequently de novo, 20$30 \%$ of cases are inherited [28]. At least eight multiplex families have been reported in the literature, and the parent from whom the deletion is inherited is most often described as "apparently unaffected" or "mildly affected" $[1,13,15-19]$. These descriptions fuel suspicion that there are individuals in the general population who have the 3q29 deletion but manifest few of the phenotypic consequences. Mildly affected individuals are less likely to be referred for genetic testing, creating an ascertainment bias in favor of the most clinically overt cases rising to medical attention. This bias may result in overestimation of the disability associated with the 3q29 deletion phenotype.

However, in reports of multiplex families identifying these "mildly affected" or "apparently unaffected" individuals, the transmitting parent is typically evaluated with only a physical examination (Table 1) [1, 13, 1519]. Neurodevelopmental and neuropsychiatric phenotypes have not been directly evaluated. These data may be extrapolated from the medical history and usually focus on the sole dimension of cognitive ability. As our appreciation of the myriad neuropsychiatric manifestations associated with 3q29 deletion syndrome has increased over time, it is important to reevaluate whether these transmitting parents are truly unaffected.

Through the 3q29 registry, we ascertained a multiplex family with three children, all with a paternally inherited 3q29 deletion. We evaluated all four affected individuals for neuropsychiatric traits, using normed, gold-standard instruments as part of our previously described comprehensive phenotyping protocol [29]. These data show that even within a single family there can be wide-ranging heterogeneity of phenotypes, and these psychiatric phenotypes may go undetected without focused evaluation by appropriate diagnosticians. Our data also reveal that in 3q29 deletion syndrome, individuals may exhibit substantial neuropsychiatric morbidity even when cognitive function is preserved. We conclude that periodic screening for neuropsychiatric illness should be prioritized for all individuals with 3q29 deletion syndrome, without regard for the presence of intellectual disability.

\section{Methods}

A 4-person multiplex family (Fig. 1) was ascertained through the 3q29 registry (3q29.org [3], housed and maintained at Emory University), and enrolled in our ongoing research study. This study was approved by Emory University's IRB (\#IRB00088012). After an informed consent process with the parents was conducted by phone, we arranged the study visit. Medical records were obtained to confirm the genetic diagnosis. Informed consent was repeated in person at the beginning of the visit. Assent was also obtained from each of the children. Each family member was evaluated using our standardized and comprehensive phenotyping protocol 
Table 1 Prior reports of 3q29 deletion multiplex families: summary of evidence for "unaffected" status of transmitting parents

\begin{tabular}{|c|c|c|c|}
\hline First author (year) & $\begin{array}{l}\text { Number of } 3 q 29 \text { deletion individuals in } \\
\text { pedigree }\end{array}$ & Evaluation of proband & Evaluation of transmitting parent \\
\hline Ballif (2008) [1] & 3 & No direct evaluation & No direct evaluation \\
\hline Monfort (2008) [18] & 2 & Physical exam & Physical exam \\
\hline Li (2009) [17] & 2 & Physical exam & Physical exam \\
\hline $\begin{array}{l}\text { Digilio (2009) [15]: } \\
\text { Family \#1 }\end{array}$ & 2 & Physical exam, cognitive evaluation & Physical exam \\
\hline $\begin{array}{l}\text { Digilio (2009) [15]: } \\
\text { Family \#2 }\end{array}$ & 2 & Physical exam & Physical exam \\
\hline $\begin{array}{l}\text { Clayton-Smith (2010) } \\
\text { [13] }\end{array}$ & 4 & $\begin{array}{l}\text { Proband: Physical exam } \\
\text { Older brother: Physical exam, cognitive } \\
\text { evaluation }\end{array}$ & $\begin{array}{l}\text { Transmitting parent: Physical exam } \\
\text { Transmitting grandparent: Physical } \\
\text { exam }\end{array}$ \\
\hline Petrin (2011) [19] & 2 & Physical exam & No evaluation ${ }^{a}$ \\
\hline Kahn (2019) [16] & 2 & Physical exam & Physical exam \\
\hline
\end{tabular}

${ }^{\mathrm{a}}$ Transmitting parent reported in Petrin et al. [19] was mosaic for the 3q29 deletion

with gold-standard instruments (Table 2, [29]). Study subjects were evaluated for cognitive ability [40, 41], anxiety $[31,37]$, executive function [33, 34], adaptive behavior [35], graphomotor ability [36], social disability [38, 39], psychosis spectrum symptoms [31, 32], and general psychopathology [30, 31]. All study subjects also had a medical history interview and physical exam conducted by an experienced medical geneticist. Instruments were scored according to established guidelines. Diagnostic cutoffs were determined based on published criteria; expert clinicians administered and scored all instruments and interpreted the scores to arrive at clinician best-estimate diagnoses. Quantitative scores were also extracted from each instrument. At the study visit, we obtained a blood sample from each family member. All blood samples were processed with an optical mapping technology (Bionano Genomics, San Diego CA) to confirm coordinates of the 3q29 deletion. Each family member was confirmed to have the canonical $1.6 \mathrm{Mb} 3 \mathrm{q} 29$ deletion with identical breakpoints chr3:195998740-197,667,295 (hg38).

\section{Case presentations} Individual II-1 (Proband): 9 yo female History

The proband was a term $3.18 \mathrm{~kg}$ infant delivered by Caesarean section (C-section) due to breech presentation. Pregnancy was otherwise uncomplicated. The child exhibited a delay in her gross motor milestones, starting to walk around 2 years of age. Other milestones were met as expected. At age 4, the child started school and some behavioral difficulties were noted. Also emerging at this time were the presence of focal seizures, café-au-lait macules, and high blood pressure secondary to renal artery stenosis (treated surgically with a stent). A clinical diagnosis of neurofibromatosis 1 (NF1) is documented in her medical records by her pediatrician at age 4 years 7 months. Existing behavioral abnormalities in the proband were atypical for NF1 prompting a chromosome microarray that detected a $1.6 \mathrm{Mb} 3 \mathrm{q} 29$ deletion. The clinical diagnosis of NF1 was confirmed by our medical geneticist (MJG) upon physical examination; thus this individual has both NF1 and 3q29 deletion syndrome.

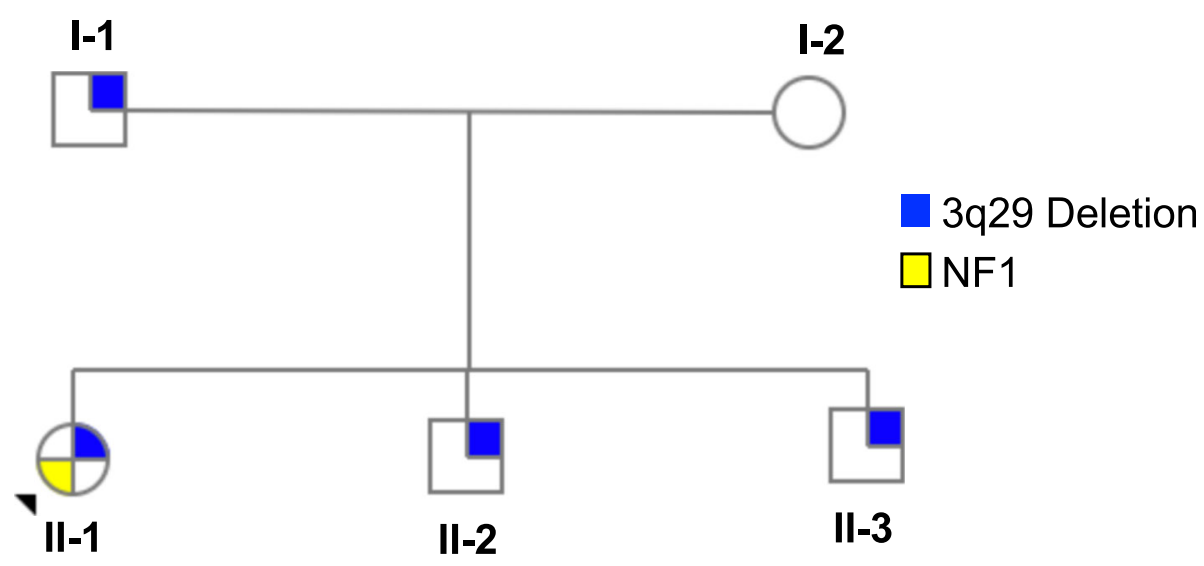

Fig. 1 The 3q29 deletion multiplex family; individuals $1-1,\|-1\|-$,2 , and II-3 were all evaluated in this study 
Table 2 Instruments and evaluations used in this study

\begin{tabular}{|c|c|c|c|c|}
\hline Phenotype and Instrument & II-1 (Proband) & II-2 (8 yo male) & II-3 (4 yo male) & I-1 (39 yo male) \\
\hline Medical history interview, Physical Exam & $x$ & $x$ & $x$ & $x$ \\
\hline \multicolumn{5}{|l|}{ General psychopathology } \\
\hline K-SADS [30] & $x$ & $x$ & $x$ & \\
\hline SCID-5-RV [31] & & & & $x$ \\
\hline \multicolumn{5}{|l|}{ Prodrome/psychosis } \\
\hline SIPS [32] & $x$ & $x$ & - & $x$ \\
\hline \multicolumn{5}{|l|}{ Executive function } \\
\hline BRIEF-2 [33] & $x$ & $x$ & - & \\
\hline BRIEF-A [34] & & & & $x$ \\
\hline \multicolumn{5}{|l|}{ Adaptive behavior } \\
\hline Vineland-3 [35] & $x$ & $x$ & $x$ & $x$ \\
\hline \multicolumn{5}{|l|}{ Visual-motor integration } \\
\hline Beery-Buktenica Developmental test of visual-motor integration, 6th ed. [36] & $x$ & $x$ & - & $x$ \\
\hline \multicolumn{5}{|l|}{ Anxiety } \\
\hline ADIS-P, ADIS-C [37] & $x$ & $x$ & - & \\
\hline SCID-5-RV [31] & & & - & $x$ \\
\hline \multicolumn{5}{|l|}{ Autism } \\
\hline ADOS-2 [38] & Module 3 & Module 3 & Module 2 & Module 4 \\
\hline ADI-R [39] & $x$ & $x$ & $x$ & - \\
\hline \multicolumn{5}{|l|}{ Cognitive Ability } \\
\hline DAS-II, School Age [40] & $x$ & $x$ & & \\
\hline DAS-II, Early Years [40] & & & $x$ & \\
\hline WASI-II [41] & & & & $x$ \\
\hline
\end{tabular}

The child has poor weight gain due to food-related fussiness and retching. Current medications include two standard medications for blood pressure control, atenolol (beta blocker) and Lisinopril (ACE inhibitor); and carbamazepine, a standard anti-convulsant widely used for treating epilepsy. Of these medications only atenolol is not approved for use in children, though off-label use in pediatric cases is documented. At the time of our evaluation, the proband was receiving special education services for attention deficit hyperactivity disorder (ADHD).

\section{Physical examination}

Weight $20.5 \mathrm{~kg}(\mathrm{z}=-2.54)$ height $121 \mathrm{~cm}(\mathrm{z}=-2.29)$ frontal orbital circumference (FOC) $50.8 \mathrm{~cm}$ (35th percentile). Body mass index (BMI) was 14.0, 5th percentile. Blood pressure was 92/53. Mild dysmorphic features were present including a prominent forehead, low set posteriorly rotated, cupped ears, upslanting palpebral fissures, and asymmetric face with left eye higher than right. She had pes planus. There were multiple café au lait macules on the abdomen, chest and back, and axillary and inguinal freckling consistent with NF1.

\section{Neuropsychiatric testing}

This child was found to have a full scale IQ (FSIQ) of 82 (12th percentile), with verbal, nonverbal reasoning, and spatial reasoning subtest scores of 90, 74, and 91, respectively (noting a significantly lower nonverbal score). Her adaptive behavior (composite score $=65$, 1st percentile) is lower than would be expected given her age and cognitive ability, indicating challenges with independent living skills. She also has clinically significant deficits in executive function ( $\mathrm{T}$ score $86,>99$ th percentile). Her visual-motor integration score (standard score 92, 30th percentile) was within the average range, but her motor coordination subtest score (standard score $=67$ ) revealed motor control deficits compared to below average visual perception (standard score $=82$ ). Upon evaluation with the Kiddie Schedule for Affective Disorders and Schizophrenia (K-SADS), the child was found to meet criteria for ADHD, combined type. She does not exhibit anxiety, ASD (although social vulnerabilities 
were present), or psychosis-spectrum symptoms (ie, subclinical prodromal or psychotic symptoms).

\section{Individual II-2: 8 yo male \\ History}

This child was a term $2.72 \mathrm{~kg}$ infant delivered by Csection due to a nuchal cord with no adverse sequelae. Delay of gross motor milestones was noted. He sat at 9 months and walked at 24 months and is yet to be completely toilet trained. Concerns about his behavior arose at age 3, concurrent with the time his older sister was diagnosed with 3q29 deletion syndrome. Genetic testing confirmed the presence of the $1.6 \mathrm{Mb} 3 \mathrm{q} 29$ deletion in this child. Persistent concerns include inability to gain weight despite normal appetite, and abnormal sleep pattern of only $\sim 3 \mathrm{~h}$ a night. No current or prior medication use was reported by the parent.

\section{Physical examination}

Weight $21.4 \mathrm{~kg}(\mathrm{z}=-1.58)$, height $126 \mathrm{~cm}(\mathrm{z}=-0.65)$, and FOC $49.5 \mathrm{~cm}$ (3rd percentile). BMI was 13.5, 1st percentile and underweight. Blood pressure was 106/75. Mild dysmorphic features were present including prominent forehead, frontal bossing, high anterior hairline, upslanted palpebral fissures, sparse eyebrows, wide nasal bridge and a dimpled chin.

\section{Neuropsychiatric testing}

This child was found to have a FSIQ of 79 (8th percentile), with verbal, nonverbal reasoning, and spatial reasoning subtest scores of 86,80 , and 79 , respectively. His adaptive behavior score of 59 falls below the 1st percentile for his age and denotes significant delays in his adaptive functioning. He has clinically significant deficits in executive function ( $\mathrm{T}$-score $=88$, $>$ 99th percentile). Graphomotor weakness is present, indicated by a Visualmotor integration (VMI) standard score of 77, which falls at the 6th percentile for his age. On the VMI, he also showed significant motor coordination deficits (standard score $=45,<1$ st percentile) compared to below average visual perception (standard score $=80$, 6th percentile). Upon evaluation with the K-SADS, this child was found to qualify for diagnoses of ADHD, combined type; disruptive mood dysregulation disorder; and conduct disorder with childhood onset. Evaluation with the Anxiety Disorders Interview Schedule (ADIS) revealed diagnoses of Separation Anxiety and a Specific Phobia (fear of the dark). Evaluation with the SIPS revealed features consistent with Attenuated Psychosis Syndrome. No evidence of ASD was present but social vulnerabilities were noted.

\section{Individual II-3: 4 yo male}

History

This child was a $2.27 \mathrm{~kg}$ term infant born by emergency $\mathrm{C}$-section due to amniotic fluid loss. He had genetic testing at 6 months of age, after his sister, father, and brother were found to have the 3q29 deletion. He had delayed motor and verbal milestones; he walked at 24 months, and his first words were at 18 months. He is currently not toilet trained. An inguinal hernia repair was performed at age 4 . He is underweight despite a normal appetite, and is followed by a dietitian. No current or prior medication use was reported by the parent.

\section{Physical examination}

Weight $11.7 \mathrm{~kg}(\mathrm{z}=-4.52)$ and height $95.6 \mathrm{~cm}(\mathrm{z}=-$ 2.91) FOC ( $48.75 \mathrm{~cm}, 10$ th percentile). BMI was 12.8 , < 1st percentile and underweight. Blood pressure was 112/ 53. Mild dysmorphic features were noted including a prominent forehead, frontal bossing, a dimple chin and deep set eyes. He has poor dentition. He had translucent skin and pes planus. He is reported to need very little sleep.

\section{Neuropsychiatric testing}

FSIQ was measured at 96 (39th percentile), with verbal, nonverbal reasoning, and spatial reasoning subtest scores of 103, 98, and 91, respectively. His adaptive behavior score of 68 (2nd percentile) indicates significant delays in his adaptive functioning given his age and cognitive ability. Due to young age, executive function, visualmotor integration, prodrome/psychosis, and anxiety were not evaluated (instruments are not normed at age 4). Symptoms endorsed by his mother using the KSADS parent interview revealed that this child was found to qualify for diagnoses of ADHD, hyperactive type. No evidence of ASD was present.

\section{Individual 1-1: 39 yo male History}

The father's genetic testing was completed when he was 34 years of age, after his daughter (the proband) was diagnosed with 3q29 deletion syndrome. He reports that he had early learning challenges. After graduating high school, he completed 3 years of postsecondary education, but did not complete his degree. He has held several jobs in the past but is currently unemployed and living on governmental assistance. He is working on obtaining a driver's license. His father and paternal grandmother are both reported to have schizophrenia; these individuals were not available for genetic testing nor direct evaluation by our team. To the best of individual I-1's knowledge, neither have had genetic testing to know if they also share the 3q29 deletion. He reported 
no prior neuropsychiatric diagnoses. He reports having difficulty falling asleep. No current or prior prescription medication use was reported.

\section{Physical examination}

Weight $77.4 \mathrm{~kg}(\mathrm{z}=0.55)$ height $165 \mathrm{~cm}(\mathrm{z}=-1.65)$, and FOC $54.5 \mathrm{~cm}$ are all within normal limits. BMI was overweight at 28.4. Blood pressure was 120/77. He had a prominent forehead but no other dysmorphic features were noted.

\section{Neuropsychiatric testing}

This individual's FSIQ is 94 (34th percentile), with verbal comprehension of 99 and perceptual reasoning of 90 . His adaptive behavior score of 61 falls below the 1st percentile for his age and denotes significant delays in adaptive functioning compared to his intact cognitive ability. Evaluation with the Behavior Rating Inventory of Executive Function, Adult edition (BRIEF-A) indicated significant executive functioning impairments ( $\mathrm{T}$-score $=73$, 97th percentile). Mild graphomotor weakness is present, indicated by a VMI standard score of 83 , which falls at the 13th percentile for his age. Visual perception and motor coordination are similarly developed (subtest standard scores $=81$ and 86 respectively). Evaluation with the Structured Clinical Interview for DSM-5, Research Version (SCID-5-RV) revealed symptoms consistent with diagnosis of a prior panic disorder, and social anxiety disorder. No autism was present but social sequelae to his other disabilities were significant. This individual also meets criteria for ADHD, inattentive type. Upon evaluation with the SCID-5-RV and the Structured Interview of Psychosis-risk Syndromes (SIPS), and an independent qualitative evaluation by our team psychiatrist (JFC), the study subject endorsed multiple symptoms consistent with psychosis, including bizarre beliefs and auditory and visual hallucinations. Based on the study subjects' report, his unusual sensory experiences most often coincided with mood disturbances and was therefore consistent with a diagnosis of schizoaffective disorder.

\section{Discussion and conclusions}

Our team has performed direct, systematic evaluation of physical, neurodevelopmental, and psychiatric phenotypes using gold-standard instruments in members of a multiplex family where four related individuals have the 3q29 deletion. Physical manifestations are moderate and include subtle facial dysmorphology, an inability to gain weight, sleep abnormalities, and mild musculoskeletal abnormalities (Table 3). In contrast, the burden of psychiatric illness among the 3q29 deletion carriers in the pedigree is substantial (Table 4). All members of the pedigree qualify for a diagnosis of ADHD and have significant delays in adaptive behavior that are far greater than expected given their level of cognitive functioning. In fact, individual I-1's (proband's father) adaptive

Table 3 Physical exam results (NE, not evaluated)

\begin{tabular}{|c|c|c|c|c|c|}
\hline System & II-1 (Proband) & II-2 (8 yo male) & II-3 (4 yo male) & $\begin{array}{l}\text { I-1 (39 yo } \\
\text { male) }\end{array}$ & $\begin{array}{l}\text { Reported Frequency in } \\
3 \text { q29 deletion syndrome }\end{array}$ \\
\hline Growth & & & & & Short stature: $24 \%^{2}$ \\
\hline Weight kg (\%tile) & $20.5(3)$ & $21.4(10)$ & $11.7 \mathrm{~kg}(<3)$ & 77.4 & Microcephaly: 55\% \\
\hline Height cm (\%tile) & $121(3)$ & $126(35)$ & $95.6(3)$ & 165 & \\
\hline FOC cm (\%tile) & $50.76(35)$ & $49.5(3)$ & $48.75(10)$ & 54.5 & \\
\hline $\begin{array}{l}\text { Facial } \\
\text { dysmorphism }\end{array}$ & $\begin{array}{l}\text { Mild } \\
\text { Poor dentition }\end{array}$ & $\begin{array}{l}\text { Mild } \\
\text { Poor dentition }\end{array}$ & $\begin{array}{l}\text { Mild } \\
\text { Poor dentition }\end{array}$ & Mild & $\begin{array}{l}\text { Dental conditions } 66 \%^{3} \\
\text { Abnormal teeth: } 20 \%^{2}\end{array}$ \\
\hline $\begin{array}{l}\text { Musculoskeletal } \\
\text { abnormalities }\end{array}$ & Flat feet & None noted & $\begin{array}{l}\text { Slight joint laxity, flat } \\
\text { feet }\end{array}$ & None noted & Ligamentous laxity: $11 \%^{2}$ \\
\hline Gl & $\begin{array}{l}\text { Feeding problems, inability to } \\
\text { gain weight, fussy eater } \\
\text { Poor appetite }\end{array}$ & $\begin{array}{l}\text { Good appetite but } \\
\text { inability to gain weight }\end{array}$ & $\begin{array}{l}\text { Good appetite but } \\
\text { inability to gain weight }\end{array}$ & $\begin{array}{l}\text { None noted } \\
\text { Reflux }\end{array}$ & Feeding problems: $41 \%^{3}$ \\
\hline Heart defects & none & none & none & none & Heart Defects: $26 \%^{3}$ \\
\hline Skin & Café au lait spots (NF1) & & Translucent skin & Psoriasis & $\begin{array}{l}\text { Abnormal skin } \\
\text { pigmentation: } 14 \%^{2}\end{array}$ \\
\hline Sleep & No difficulties reported & Sleeps only $\sim 3 \mathrm{~h} /$ night & Needs little sleep & $\begin{array}{l}\text { Difficulty } \\
\text { falling } \\
\text { asleep }\end{array}$ & $\mathrm{NE}$ \\
\hline Other & $\begin{array}{l}\text {-Focal epilepsy } \\
\text {-Renal artery stenosis s/p stent/ } \\
\text { HTN } \\
\text {-Right eye wanders } \\
\text {-Gags often } \\
\text {-Hypermobility }\end{array}$ & $\begin{array}{l}\text {-Not completely toilet } \\
\text { trained } \\
\text {-Aversion to loud noises } \\
\text {-Cold intolerance }\end{array}$ & $\begin{array}{l}\text {-Not toilet trained } \\
\text {-Inguinal hernia repair } \\
\text {-Sensitive hearing (likes } \\
\text { ear defenders) } \\
\text {-Poor coordination } \\
\text {-Heat/cold intolerance }\end{array}$ & -Migraines & -Seizures: $5 \%^{3}$ \\
\hline
\end{tabular}


Table 4 Neurodevelopmental and neuropsychiatric morbidity (NE, not evaluated)

\begin{tabular}{|c|c|c|c|c|c|}
\hline Phenotype & II-1 (Proband) & II-2 (8 yo male) & II-3 (4 yo male) & I-1 (39 yo male) & $\begin{array}{l}\text { Reported Frequency in 3q29 } \\
\text { deletion syndrome }\end{array}$ \\
\hline $\begin{array}{l}\text { General } \\
\text { psychopathology }\end{array}$ & ADHD, combined type & $\begin{array}{l}\text { ADHD, Combined type; } \\
\text { Disruptive Mood } \\
\text { Dysregulation Disorder; } \\
\text { Conduct Disorder with } \\
\text { Childhood Onset }\end{array}$ & $\begin{array}{l}\text { ADHD, } \\
\text { hyperactive } \\
\text { type }\end{array}$ & ADHD, inattentive type & ADHD: NE \\
\hline $\begin{array}{l}\text { Prodrome/ } \\
\text { psychosis }\end{array}$ & - & $\begin{array}{l}\text { Attenuated Psychosis } \\
\text { Syndrome }\end{array}$ & $\mathrm{NE}$ & Schizoaffective disorder & Psychosis: $5 \%^{3}$ \\
\hline $\begin{array}{l}\text { Executive } \\
\text { function } \\
\text { T-score (\%tile) }\end{array}$ & $\begin{array}{l}\text { Clinically Significant } \\
\text { Deficits } 86(>99)\end{array}$ & $\begin{array}{l}\text { Clinically Significant Deficits } \\
88(>99)\end{array}$ & NE & $\begin{array}{l}\text { Clinically Significant } \\
\text { Deficits } \\
73(97)\end{array}$ & NE \\
\hline $\begin{array}{l}\text { Adaptive } \\
\text { behavior } \\
\text { Standard Score } \\
\text { (\%tile) }\end{array}$ & $\begin{array}{l}\text { Significant Delays } \\
65(1)\end{array}$ & $\begin{array}{l}\text { Significant Delays } \\
59(<1)\end{array}$ & $\begin{array}{l}\text { Significant } \\
\text { Delays } \\
68(2)\end{array}$ & $\begin{array}{l}\text { Significant Delays } \\
61(<1)\end{array}$ & Global Devel Delay $41 \%^{3}$ \\
\hline $\begin{array}{l}\text { Visual-motor } \\
\text { integration } \\
\text { Standard Score } \\
\text { (\%tile) }\end{array}$ & $\begin{array}{l}\text { Average Range } \\
92(30)\end{array}$ & $\begin{array}{l}\text { Significant Delays } \\
77(6)\end{array}$ & $\begin{array}{l}\text { Low } \\
83(13)\end{array}$ & $\begin{array}{l}\text { Low } \\
83(13)\end{array}$ & $\mathrm{NE}$ \\
\hline Anxiety & - & $\begin{array}{l}\text { Separation Anxiety; Specific } \\
\text { Phobia of the Dark }\end{array}$ & $\mathrm{NE}$ & $\begin{array}{l}\text { Panic disorder; social } \\
\text { anxiety disorder }\end{array}$ & Anxiety: $19 \%^{3}$ \\
\hline Autism & - & - & - & - & Autism: $26 \%^{3}$ \\
\hline $\begin{array}{l}\text { Cognitive Ability } \\
\text { Standard Score } \\
\text { (\%tile) }\end{array}$ & $\begin{array}{l}\text { Below Average } \\
82(12)\end{array}$ & $\begin{array}{l}\text { Low } \\
79(8)\end{array}$ & $\begin{array}{l}\text { Average } \\
96(39)\end{array}$ & $\begin{array}{l}\text { Average } \\
94(34)\end{array}$ & Intellectual disability: $92 \%^{2}$ \\
\hline
\end{tabular}

deficits were evident in his inability to sustain a job and function independently in many aspects of his life. Three individuals who were evaluated have clinically significant deficits in executive function, and two children have deficits in motor coordination. In two individuals, anxiety disorders were present, and in these same two individuals, evidence of a psychotic disorder is present. Individual II-1 (the proband) had a prior diagnosis of ADHD but no other neurodevelopmental or psychiatric diagnoses were reported in any member of the family. These data provide further evidence that the disability associated with 3q29 deletion syndrome is predominantly in the neuropsychiatric domain. The high burden of mental illness associated with the 3q29 deletion is an impediment to quality of life and independent functional living, but may be undetected without deliberate and focused evaluation.

Prior reports of multiplex families where transmitting parents are reported as "unaffected" or "mildly affected" have had an outsized effect on our interpretation of the 3q29 deletion phenotypic spectrum, introducing skepticism about the burden of illness associated with the deletion $[1,13,15-19]$. The existence of unaffected transmitting parents implies that there are individuals with the 3q29 deletion in the general population who are functioning within the average or above average range. These higher functioning individuals are not typically ascertained through genetic testing, thus it has been suggested that only the most severe cases of 3q29 deletion syndrome are described in the literature [10]. The implication of prior multiplex case reports is that the severity of the 3q29 deletion phenotype is overestimated. However, a reexamination of these multiplex reports reveals that phenotypic evaluation of transmitting parents has been limited to physical traits only, with no formal evaluation of cognitive ability or psychiatric illness. Many of these multiplex reports date back 10 years or more, when the association between the 3q29 deletion and psychiatric illness was not appreciated. In light of new findings that the 3q29 deletion is associated with generalized anxiety disorder, social disability, and increased risk for both autism and schizophrenia [2-6], it is appropriate to reconsider prior multiplex reports. Without direct evaluation and deliberate solicitation of psychiatric phenotypes, it is not known whether the transmitting parents reported in past case reports are truly unaffected. We note that in the multiplex pedigree we report on here, if criteria from prior case reports were used, the transmitting father would also have been judged to be only mildly affected. It was only through direct evaluation with appropriate instruments, and consideration of his psychosocial functioning and history, that his degree of disability emerged. Our data suggest a competing hypothesis: the adverse manifestations of the $3 q 29$ deletion phenotype may be underestimated, as many prior case reports may not have ascertained the 
full spectrum of neurodevelopmental and psychiatric phenotypes in individuals with the 3q29 deletion.

In early descriptions of 3q29 deletion syndrome, subjects were noted to have "mild to moderate intellectual disability." Subsequent case reports have therefore typically focused on the dimension of cognitive ability. However, in at least one prior report there is a hint that 3q29 comorbidity may be uncoupled from intellectual function. Cobb et al. reported on a 6.75 year old male with a de novo 3q29 deletion, with full-scale IQ measured at 84, well within the normal range [10]. However, this child was noted to have features consistent with autism and ADHD, inattentive type. The phenotypic features of Cobb et al's patient are consistent with the individuals reported here, where cognitive measures for all 3q29 deletion individuals in the pedigree are within the normal range, yet multiple comorbid psychiatric diagnoses are present in each individual. Taken together, these data imply that the psychiatric phenotypes observed in 3q29 deletion syndrome are partially independent of intellectual function, and further suggest that the measure of cognitive ability is not a useful proxy for overall behavioral disability in individuals with 3q29 deletion syndrome. A larger sample of well-phenotyped 3q29 deletion study subjects is required to confirm these findings.

$3 q 29$ deletion syndrome has a heterogeneous presentation with variable penetrance of medical, neurodevelopmental and neuropsychiatric phenotypes [2, 3, 7]. This has been seen in other genomic disorders, such as 22q11.2 deletion syndrome [42] and 16p11.2 deletion and duplication [43, 44]. Various hypotheses have been invoked to explain this heterogeneity, including the presence of individual rare or common genetic variants that may act as modifier loci [45], genetic background effects [46], and/or polygenic risk scores [47, 48]. In the family evaluated in the current study, there is concordance among multiple neurodevelopmental and neuropsychiatric phenotypes that are exhibited (ADHD, executive function, adaptive behavior, visual-motor deficits are present in all evaluated) or not present (no member of the pedigree was diagnosed with autism spectrum disorder), suggesting that either these phenotypes are less sensitive to modifying influences, or the possible modifiers (whether genetic or environmental) are present in all family members. In contrast medical phenotypes are more variable, as are measures of intellectual function. FSIQ ranges from low (79) to average (96). In addition, two members of the pedigree were found to have a psychotic disorder. Individual III-3 was only 4 years of age at the time of evaluation; at this age psychotic phenotypes cannot be reliably assessed. The proband (Individual II-1) does not exhibit psychotic features at this time, but has not moved through the age at risk. Future follow up of this family would be useful to assess concordance of psychotic phenotypes. The current data suggest that medical phenotypes, intellectual function, and psychotic manifestations may be more susceptible to modifying influences. A larger sample of well-phenotyped individuals with 3q29 deletion syndrome will be required to support or refute these observations.

In conclusion, we report a multiplex family where multiple individuals have the 3q29 deletion syndrome and varied neurodevelopmental and psychiatric manifestations. These data serve to expand upon the 3q29 deletion phenotype and suggest that disability associated with the syndrome is not restricted to or solely a consequence of intellectual deficit. Our data further suggest that care and management of individuals with the 3q29 deletion should include screening for neurodevelopmental and psychiatric traits at multiple timepoints across the lifespan.

\section{Abbreviations}

ADHD: Attention Deficit Hyperactivity Disorder; ADIS: Anxiety Disorders Interview Schedule; ASD: Autism Spectrum Disorder; BMI: Body Mass Index; BRIEF: Behavior Rating Inventory of Executive Function; CNV: Copy Number Variant; C-Section: Caesarian section; FOC: Frontal Orbital Circumference; FSIQ: Full Scale Intelligence Quotient; KSADS: Kiddie Schedule for Affective Disorders and Schizophrenia; NF1: Neurofibramatosis 1; SCID-5-RV: Structured Clinical Interview for DSM-5, Research Version; SIPS: Structured Interview of Psychosis-risk Syndromes; VMI: Visual-Motor Integration

\section{Acknowledgements \\ We want to thank the very special family who participated in this research; we are grateful for the opportunity to learn from them. We want to acknowledge The Emory 3q29 Project team members: Hallie Averbach, Gary J. Bassell, Shanthi Cambala, Grace Carlock, Tamara Caspary, David Cutler, Paul A. Dawson, Michael P. Epstein, Henry R. Johnston, Elizabeth J. Leslie, Longchuan Li, Bryan Mak, Tamika Malone, Trenell Mosely, Rebecca M. Pollak, Ryan Purcell, Timothy Rutkowski, Jason Schroeder, Esra Sefik, Brittney Sholar, Nikisha Sisodoya, Sarah Schultz, Steven Sloan, Stephen T. Warren, David Weinshenker, Zhexing Wen, Michael E. Zwick.}

\section{Authors' contributions}

LB assessed anxiety phenotypes and interpreted the data. JFC performed qualitative psychiatric assessment of the adult participant. MTE performed qualitative psychiatric assessment of pediatric participants. RE and KG administered the KSADS, SCID, and SIPS to study participants and interpreted the data. MJG, RSR, and SK administered medical history interviews and physical exams to all study participants, and recorded and interpreted the data. CK and CAS evaluated cognitive ability, VMI, executive function, adaptive behavior, and autism phenotypes in all study subjects. MM recruited and consented study subjects and coordinated the study visit. EW supervised RE and KG and interpreted data from assessments. JGM conceived of the study and led the writing of the manuscript. All authors participated in the crafting of the manuscript. The author(s) read and approved the final manuscript.

\section{Funding}

This research was funded by the National Institute of Mental Health $\left(\mathrm{NIMH}_{\text {, }}\right.$ R01 MH110701). The funder had no role in the design of the study, the collection, analysis and interpretation of the data, nor in the writing of the manuscript.

\section{Availability of data and materials}

All data generated or analyzed during this study are included in Tables 2 and 3. Additional details are available from the corresponding author on reasonable request. 


\section{Ethics approval and consent to participate}

This study was reviewed and approved by Emory University's Institutional Review Board (IRB00088012). All participating study subjects gave informed consent. Individuals younger than age 16 gave assent to participate.

\section{Consent for publication}

A copy of this manuscript was provided to the subjects participating in this study; written and verbal consent for publication of the data herein was obtained from participating study subjects.

\section{Competing interests}

C.A.S. receives royalties for the Vineland-3 from Pearson Clinical. The remaining authors declare that they have no competing interests.

\section{Author details}

'Department of Human Genetics, Emory University School of Medicine, Whitehead 305M, 615 Michael Street, Atlanta, GA 30322, USA. ²Department of Pediatrics, Emory University School of Medicine, Atlanta, USA. ${ }^{3}$ Marcus Autism Center, Children's Healthcare of Atlanta and Emory University School of Medicine, Atlanta, USA. ${ }^{4}$ Departments of Human Genetics and Psychiatry and Behavioral Science, Emory University School of Medicine, Atlanta, USA. ${ }^{5}$ Department of Psychiatry and Behavioral Science, Emory University School of Medicine, Atlanta, USA. 'Department of Psychology, Emory University, Atlanta, USA. ${ }^{7}$ Neurodevelopmental Assessment \& Consulting Services, Decatur, USA. ${ }^{8}$ Department of Epidemiology, Rollins School of Public Health, Emory University, Atlanta, USA.

\section{Received: 12 February 2020 Accepted: 12 April 2020}

Published online: 22 April 2020

\section{References}

1. Ballif BC, Theisen A, Coppinger J, Gowans GC, Hersh JH, Madan-Khetarpal S, et al. Expanding the clinical phenotype of the 3 q29 microdeletion syndrome and characterization of the reciprocal microduplication. Mol Cytogenet. 2008;1:8.

2. Cox DM, Butler MG. A clinical case report and literature review of the 3929 microdeletion syndrome. Clin Dysmorphol. 2015;24(3):89-94.

3. Glassford MR, Rosenfeld JA, Freedman AA, Zwick ME, Mulle JG. Unique rare chromosome disorder support G. novel features of 3q29 deletion syndrome: results from the 3q29 registry. Am J Med Genet A. 2016;170(4):999-1006.

4. Sanders SJ, He X, Willsey AJ, Ercan-Sencicek AG, Samocha KE, Cicek AE, et al. Insights into autism Spectrum disorder genomic architecture and biology from 71 risk loci. Neuron. 2015:87(6):1215-33.

5. Mulle JG. The $3 q 29$ deletion confers $>40$-fold increase in risk for schizophrenia. Mol Psychiatry. 2015;20(9):1028-9.

6. Marshall CR, Howrigan DP, Merico D, Thiruvahindrapuram B, Wu W, Greer DS, et al. Contribution of copy number variants to schizophrenia from a genome-wide study of 41,321 subjects. Nat Genet. 2017;49(1):27-35.

7. Pollak RM, Murphy MM, Epstein MP, Zwick ME, Klaiman C, Saulnier CA, et al. Neuropsychiatric phenotypes and a distinct constellation of ASD features in 3 q29 deletion syndrome: results from the 3q29 registry. Mol Autism. 2019; 10:30.

8. Szatkiewicz JP, O'Dushlaine C, Chen G, Chambert K, Moran JL, Neale BM, et al. Copy number variation in schizophrenia in Sweden. Mol Psychiatry. 2014;19(7):762-73.

9. Willatt L, Cox J, Barber J, Cabanas ED, Collins A, Donnai D, et al. $3 q 29$ microdeletion syndrome: clinical and molecular characterization of a new syndrome. Am J Hum Genet. 2005;77(1):154-60.

10. Cobb W, Anderson A, Turner C, Hoffman RD, Schonberg S, Levin SW. 1.3 Mb de novo deletion in chromosome band 3q29 associated with normal intelligence in a child. Eur J Med Genet. 2010;53(6):415-8.

11. Baynam G, Goldblatt J, Townshend S. A case of 3q29 microdeletion with novel features and a review of cytogenetically visible terminal $3 q$ deletions. Clin Dysmorphol. 2006;15(3):145-8.

12. Citta S, Buono S, Greco D, Barone C, Alfei E, Bulgheroni S, et al. 3q29 microdeletion syndrome: cognitive and behavioral phenotype in four patients. Am J Med Genet A. 2013;161A(12):3018-22.

13. Clayton-Smith J, Giblin C, Smith RA, Dunn C, Willatt L. Familial 3q29 microdeletion syndrome providing further evidence of involvement of the $3 q 29$ region in bipolar disorder. Clin Dysmorphol. 2010;19(3):128-32.
14. Dasouki MJ, Lushington GH, Hovanes K, Casey J, Gorre M. The 3q29 microdeletion syndrome: report of three new unrelated patients and in silico "RNA binding" analysis of the 3q29 region. Am J Med Genet A. 2011; 155A(7):1654-60.

15. Digilio MC, Bernardini L, Mingarelli R, Capolino R, Capalbo A, Giuffrida MG, et al. 3q29 microdeletion: a mental retardation disorder unassociated with a recognizable phenotype in two mother-daughter pairs. Am J Med Genet A. 2009;149A(8):1777-81.

16. Khan WA, Cohen N, Scott SA, Pereira EM. Familial inheritance of the $3 q 29$ microdeletion syndrome: case report and review. BMC Med Genet. 2019; 12(1):51.

17. Li F, Lisi EC, Wohler ES, Hamosh A, Batista DA. $3 q 29$ interstitial microdeletion syndrome: an inherited case associated with cardiac defect and normal cognition. Eur J Med Genet. 2009;52(5):349-52.

18. Monfort S, Rosello M, Orellana C, Oltra S, Blesa D, Kok K, et al. Detection of known and novel genomic rearrangements by array based comparative genomic hybridisation: deletion of ZNF533 and duplication of CHARGE syndrome genes. J Med Genet. 2008;45(7):432-7.

19. Petrin AL, Daack-Hirsch S, L'Heureux J, Murray JC. A case of $3 q 29$ microdeletion syndrome involving oral cleft inherited from a nonaffected mosaic parent: molecular analysis and ethical implications. Cleft Palate Craniofac J. 2011;48(2):222-30.

20. Quintero-Rivera F, Sharifi-Hannauer P, Martinez-Agosto JA. Autistic and psychiatric findings associated with the 3 q29 microdeletion syndrome: case report and review. Am J Med Genet A. 2010;152A(10):2459-67.

21. Sagar A, Bishop JR, Tessman DC, Guter S, Martin CL, Cook EH. Cooccurrence of autism, childhood psychosis, and intellectual disability associated with a de novo 3q29 microdeletion. Am J Med Genet A. 2013; $161 \mathrm{~A}(4): 845-9$.

22. Tyshchenko N, Hackmann K, Gerlach EM, Neuhann T, Schrock E, Tinschert S. $1.6 \mathrm{Mb}$ deletion in chromosome band $3 \mathrm{q} 29$ associated with eye abnormalities. Eur J Med Genet. 2009:52(2-3):128-30.

23. Rossi E, Piccini F, Zollino M, Neri G, Caselli D, Tenconi R, et al. Cryptic telomeric rearrangements in subjects with mental retardation associated with dysmorphism and congenital malformations. J Med Genet. 2001;38(6): 417-20.

24. Koolen DA, Nillesen WM, Versteeg MH, Merkx GF, Knoers NV, Kets M, et al. Screening for subtelomeric rearrangements in 210 patients with unexplained mental retardation using multiplex ligation dependent probe amplification (MLPA). J Med Genet. 2004;41(12):892-9.

25. Krepischi-Santos AC, Vianna-Morgante AM, Jehee FS, Passos-Bueno MR, Knijnenburg J, Szuhai K, et al. Whole-genome array-CGH screening in undiagnosed syndromic patients: old syndromes revisited and new alterations. Cytogenet Genome Res. 2006;115(3-4):254-61.

26. Shao L, Shaw CA, Lu XY, Sahoo T, Bacino CA, Lalani SR, et al. Identification of chromosome abnormalities in subtelomeric regions by microarray analysis: a study of 5,380 cases. Am J Med Genet A. 2008;146A(17):2242-51.

27. Malt EA, Juhasz K, Frengen A, Wangensteen T, Emilsen NM, Hansen B, et al. Neuropsychiatric phenotype in relation to gene variants in the hemizygous allele in 3q29 deletion carriers: a case series. Mol Genet Genomic Med. 2019;7(9):e889.

28. Mulle JG, Gambello MJ, Cook EH, Rutkowski TP, Glassford M. 3q29 Recurrent Deletion. In: Adam MP, Ardinger HH, Pagon RA, Wallace SE, LH B, Stephens K, editors. editors GeneReviews((R)). Seattle: University of Washington, Seattle 1993.

29. Murphy MM, Lindsey Burrell T, Cubells JF, Espana RA, Gambello MJ, Goines $K C B$, et al. Study protocol for the Emory 3q29 project: evaluation of neurodevelopmental, psychiatric, and medical symptoms in 3q29 deletion syndrome. BMC Psychiatry. 2018;18(1):183.

30. Kaufman J, Birmaher B, Brent D, Rao U, Flynn C, Moreci P, et al. Schedule for affective disorders and schizophrenia for school-age children-present and lifetime version (K-SADS-PL): initial reliability and validity data. J Am Acad Child Adolesc Psychiatry. 1997;36(7):980-8.

31. First M, Williams J, Karg R, Spitzer R. User's guide for the structured clinical interview for DSM-5 disorders, research version (SCID-5-RV). Arlington: American Psychiatric Association; 2015.

32. Miller TJ, McGlashan TH, Rosen JL, Cadenhead K, Cannon T, Ventura J, et al. Prodromal assessment with the structured interview for prodromal syndromes and the scale of prodromal symptoms: predictive validity, interrater reliability, and training to reliability. Schizophr Bull. 2003;29(4):703-15.

33. Gioia G, Isquith PK, Guy S, Kenworthy L. Behavior Rating Inventory of Executive Function. 2nd ed. Lutz: PAR; 2015 
34. Roth $\mathrm{R}$, Isquith $\mathrm{P}$, Gioia $\mathrm{G}$. Behavior rating inventory of executive functionsadult version (BRIEF-A). Lutz: PAR; 2005.

35. Sparrow S, Cicchetti D, Saulnier CA. Vineland adaptive behavior scales (comprehensive parent/caregiver interview). 3rd ed. ed. Circle Pines: American Guidance Service; 2016.

36. Beery K, Beery N. The Beery-Buktenica visual motor Intergration test. 6th ed. ed. Bloomington: Pearson; 2010.

37. Silverman W, Albano A. Anxiety disorders interview schedule-IV (child and parent versions). San Antonio: Graywind Publications; 1996.

38. Lord C, Risi S, Lambrecht L, Cook EH Jr, Leventhal BL, DiLavore PC, et al. The autism diagnostic observation schedule-generic: a standard measure of social and communication deficits associated with the spectrum of autism. J Autism Dev Disord. 2000;30(3):205-23.

39. Rutter M, LeCouteur A, Lord C. Autism diagnostic interview, revised. Los Angeles: Western Psychological Service; 2003.

40. Elliott CD. Differential abilities scales. 2nd ed. ed. Harcourt Assessment: San Antonio; 2007

41. Wechsler D. Wechsler abbreviated scale of intelligence. 2nd ed. ed. Bloomington: Pearson; 2011.

42. McDonald-McGinn DM, Sullivan KE, Marino B, Philip N, Swillen A, Vorstman JA, et al. 22q11.2 deletion syndrome. Nat Rev Dis Primers. 2015;1:15071.

43. Niarchou M, Chawner S, Doherty JL, Maillard AM, Jacquemont S, Chung WK, et al. Psychiatric disorders in children with 16p11.2 deletion and duplication Transl Psychiatry. 2019;9(1):8.

44. D'Angelo D, Lebon S, Chen Q, Martin-Brevet S, Snyder LG, Hippolyte L, et al. Defining the effect of the 16p11.2 duplication on cognition, behavior, and medical comorbidities. JAMA Psychiatry. 2016;73(1):20-30.

45. Girirajan S, Rosenfeld JA, Cooper GM, Antonacci F, Siswara P, Itsara A, et al. A recurrent 16p12.1 microdeletion supports a two-hit model for severe developmental delay. Nat Genet. 2010;42(3):203-9.

46. Moreno-De-Luca A, Evans DW, Boomer KB, Hanson E, Bernier R, Goin-Kochel RP, et al. The role of parental cognitive, behavioral, and motor profiles in clinical variability in individuals with chromosome 16p11.2 deletions. JAMA Psychiatry. 2015;72(2):119-26.

47. Oetjens MT, Kelly MA, Sturm AC, Martin CL, Ledbetter DH. Quantifying the polygenic contribution to variable expressivity in eleven rare genetic disorders. Nat Commun. 2019:10(1):4897.

48. Bergen SE, Ploner A, Howrigan D, Group CNVA, the Schizophrenia Working Group of the Psychiatric Genomics C, O'Donovan MC, et al. Joint Contributions of rare copy number variants and common SNPs to risk for schizophrenia. Am J Psychiatry. 2019;176(1):29-35.

\section{Publisher's Note}

Springer Nature remains neutral with regard to jurisdictional claims in published maps and institutional affiliations.

Ready to submit your research? Choose BMC and benefit from:

- fast, convenient online submission

- thorough peer review by experienced researchers in your field

- rapid publication on acceptance

- support for research data, including large and complex data types

- gold Open Access which fosters wider collaboration and increased citations

- maximum visibility for your research: over $100 \mathrm{M}$ website views per year

At $\mathrm{BMC}$, research is always in progress.

Learn more biomedcentral.com/submissions 